\title{
OS SUJEITOS EGRESSOS PRISIONAIS E O PROCESSO DE (RE)INSERÇÃO SOCIAL
}

PRISON EGRESSES SUBJECTS AND THE PROCESS OF (RE)INSERTION

LOS SUJETOS EGRESOS DE LA CÁRCEL Y EL PROCESO DE (RE)INSERCIÓN SOCIAL

\author{
Thalita Mara dos Santos* \\ Luiz Carlos Avelino da Silva**
}

\begin{abstract}
RESUMO
O presente trabalho, fruto da dissertação de mestrado intitulada "Os sujeitos egressos prisionais: o retorno à liberdade e a (re)inserção social”, teve como objetivo abordar o processo de reinserção social dos egressos prisionais na perspectiva desses indivíduos. Constitui-se como uma pesquisa qualitativa, com a utilização do método interpretativo da Psicanálise. Sete egressos prisionais da cidade de Uberlândia (MG) foram sujeitos deste estudo, por meio de entrevistas semiestruturadas, com gravação de áudio e transcrição das entrevistas, as quais foram posteriormente analisadas sob a perspectiva psicanalítica. Constatou-se com os procedimentos o fascínio que o crime (especialmente o tráfico de drogas), como um meio de vida, exerce sobre os jovens pobres - e sobre o período de estadia na prisão - toda a crueza que ela abarca. Observou-se, sobretudo com relação ao processo de reinserção social dos egressos prisionais, a necessidade de relativizar a concepção acerca do significado de liberdade e reinserção para esses sujeitos.
\end{abstract}

Palavras-chave: Egressos Prisionais. Sujeito. Reinserção Social.

\begin{abstract}
This work, as a result of the master's thesis entitled "Prison egresses subjects: the return to freedom and the social (re)integration", aimed to approach the process of social reintegration of prison egresses from their own perspective. It constitutes a qualitative study, using the interpretative method of Psychoanalysis. Seven prison egresses from the city of Uberlândia, state of Minas Gerais, were subjects from this study through semi-structured interviews with audio recording and transcription of the interviews that were subsequently analyzed in a psychoanalytic perspective. With the procedures, it was found the fascination that crime (especially drug trafficking), as a way of life, exerts on poor adolescents - and on the period of permanence in
\end{abstract}

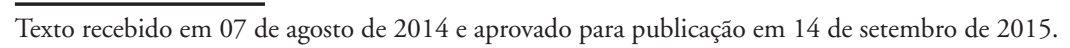

* Psicóloga Clínica e Social, Mestre em Psicologia Aplicada pela Universidade Federal de Uberlândia. Uberlândia (MG), Brasil. E-mail: thalitapsico@yahoo.com.br.

** Doutor em Psicologia Escolar e do Desenvolvimento Humano pela Universidade de São Paulo (2004) e docente do Instituto de Psicologia da Universidade Federal de Uberlândia. Uberlândia (MG), Brasil. E-mail: luizavelino@yahoo.com.br. 
prison - all the cruelty that it embraces. It was observed, mainly regarding the social reintegration process of prison egresses, the necessity to relativize the conception about the meaning of freedom and reintegration for these subjects.

Keywords: Prison Egresses. Subject. Social Reintegration.

\section{RESUMEN}

Este trabajo es resultado de la tesis de maestría intitulada "Los sujetos egresos de la cárcel: el retorno a la libertad y la (re)inserción social", tuvo por objetivo abordar el proceso de reinserción social de los egresos de la cárcel desde la perspectiva de estos sujetos. Constituye un estudio cualitativo utilizando el método interpretativo del Psicoanálisis. Siete egresos de la cárcel de Uberlândia (MG) fueron los sujetos de este estudio, por medio de entrevistas semi-estructuradas, con grabación de audio y transcripción de las entrevistas que después fueron analizadas bajo la perspectiva psicoanalítica. Se percibió con los procedimientos la fascinación que la delincuencia (especialmente el tráfico de drogas) como una forma de vida tiene en los jóvenes pobres - y sobre el período de estancia en la cárcel - toda la crudeza que ella envuelve. Se observó principalmente con respecto a la reinserción social de los egresos de la cárcel, la necesidad de relativizar la concepción acerca del significado de libertad y reinserción para estos sujetos.

Palabras-clave: Egresos de La Cárcel. Sujeto. Reinserción Social.

\section{INTRODUÇÃO}

A expressão "egressos prisionais", que caracteriza as pessoas que passaram pela $\triangle$ privação de liberdade, consta na Lei de Execução Penal (LEP) n. 7.210 de 111 de julho de 1984, no Art. 26, que dispóe: "Considera-se egresso para os efeitos desta lei: I) o liberado definitivo, pelo prazo de um ano a contar da saída do estabelecimento; II) o liberado condicional, durante o período de prova" (Lei n. 7.210, 1984).

De fato, a adoção de apenas tal aspecto legal para denominar essas pessoas consiste em um reducionismo irresponsável que não contempla a complexidade que envolve a temática. Sendo assim, umas das premissas que acompanham as discussões sobre os egressos prisionais incide na necessidade de abordar as condiçóes sociais/existenciais que antecedem a entrada no sistema prisional, o período de estadia nas cadeias, bem como o processo de transição para a liberdade após o cumprimento da pena. 
O período pré-penal dos "sujeitos típicos" que passaram pelo sistema prisional, ou seja, indivíduos que aumentam a massa carcerária por possuírem atributos sociais comuns, conforme aponta o Sistema de Informações do Sistema Penitenciário (Brasil, 2007) - baixa renda, pouca escolaridade, acesso precário à alimentação, ao saneamento e à saúde -, não contam com uma assistência judiciária adequada no acompanhamento do processo penal. Essa fase é marcada por condições degradantes da dignidade humana que fazem parte da realidade social brasileira e mantêm estreita relação com o fenômeno da criminalidade. Conforme Baratta (2002), a criminalidade compreende um processo de recrutamento de uma delimitada parcela da população dos estratos sociais inferiores.

A relação entre a pobreza e a criminalidade não é um fenômeno natural, mas uma construção social reforçada pela parcialidade do sistema judiciário que elege uma parte da população como alvo das ações penais. Desse modo, a população carcerária é composta, na sua maioria, por pessoas pobres, mas não representa fielmente o conjunto total de infratores (Wacquant, 2001; Zaluar, 1996).

Com a entrada no sistema prisional, os sujeitos são desapropriados de sua autonomia e passam a ser observados e controlados em todas as atividades diárias. Goffman (2008) inclui as prisões dentro do grupo das instituiçōes totais, as quais possuem um caráter de fechamento e visam a controlar todas as disposiçôes dos indivíduos, ao mesmo tempo em que protegem a sociedade mais ampla daqueles que foram isolados.

A rotina artificial, as regras, as relações de poder e os mecanismos domesticadores do ambiente prisional (Foucault, 1987) conferem aos indivíduos presos novos padrões de referências e de ajustamento à cultura dos cárceres, os quais geram insatisfações e desordens psicológicas e criam sujeitos marcados subjetivamente por tal experiência.

Nesse sentido, ao refletir sobre as pessoas que passaram pela privação de liberdade, é relevante considerar que, antes de presidiários ou de egressos prisionais, eles são sujeitos, seres humanos que podem, entre outras possibilidades, traçar um caminho de liberdade-prisão-liberdade que não é inteligível somente por meio da razão.

Cabe esclarecer o que pretendemos quando usamos a palavra sujeito. Com a introdução do conceito freudiano de inconsciente, a noção de sujeito cognoscente que prevalecia juntamente com os ideais iluministas do século XVIII foi radicalmente alterada, sendo que o sujeito dentro da visão psicanalítica se atenta à inauguração do que é chamado de metapsicologia freudiana. Conforme Freud (1915/1996), a metapsicologia, tal como o prefixo meta indica, transcende a 
Psicologia, configurando-se como um campo teórico relacionado ao que vai além da consciência.

Faz-se necessário reconhecer que o termo sujeito, embora tenha relevância central, não foi utilizado por Freud, e a compreensão psicanalítica sobre o assunto aparece apenas de forma implícita nos seus documentos. Além disso, dentro do âmbito da Psicanálise, passa a existir não apenas um conceito de sujeito, e sim várias noções a esse respeito.

Ogden (1996) faz uma leitura da definição dos sujeitos em psicanálise utilizando-se do conceito de dialética do filósofo Hegel. Ele concebe o sujeito a partir de um movimento contínuo de contraposição de partes opostas rumo a uma integração que não se realizaria completamente.

Seguindo essa noção de dialética hegeliana, Ogden (1996) discorre sobre a noção de sujeito para Freud, Klein e Winnicott. Para Freud (1938/1940/1996), o consciente e o inconsciente são sistemas coexistentes e complementares, em que o processo de continuidade e diferenciação se torna o gerador da experiência; logo: "O sujeito, para Freud, deve ser procurado na fenomenologia daquilo que se encontra nas relações entre consciência e inconsciente" (Ogden, 1996, p. 15).

Klein (1935/1996) discorre sobre as organizações psíquicas utilizando-se do conceito de "posições" (esquizo-paranoide e depressiva) para diferenciar os agrupamentos de afetos - como angústias e defesas - das fases do desenvolvimento, pois estes podem ocorrer em diferentes estágios da vida.

Associada a cada uma das posiçōes está uma qualidade particular de angústia, além de formas de defesa e relação objetal, um tipo de simbolização e uma qualidade de subjetividade. Juntas, essas qualidades da experiência constituem um estado de ser característico de cada uma das posições (Ogden, 1996, p. 30).

Já o sujeito, para Winnicott (1951), compreende um inovador conceito de espaço potencial entre mãe e bebê, uma área intermediária entre a realidade e a fantasia permeada de movimentos dialéticos (interno versus externo e unido versus separado) que constituem o sujeito: "Cada uma dessas dialéticas representa uma faceta diferente da interdependência entre subjetividade e intersubjetividade" (Ogden, 1996, p. 45).

Lacan (1966/1988) foi o autor que estabeleceu uma conceituação de sujeito da psicanálise como o sujeito do inconsciente e o sujeito do desejo. Para ele, o sujeito não "nasce" ou se "desenvolve", mas se constitui no encontro com o Outro. A categoria de Outro (utilizando "o" maiúsculo) apresentada por Lacan trata não apenas do adulto responsável pela sobrevivência do neonatal desamparado, mas 
também do adulto responsável pela inserção do recém-nascido em um cenário de mundo social, cultural e simbólico já preexistente. Nesses termos, o Outro não é simplesmente uma pessoa física, mas uma ordem simbólica introduzida por quem é responsável por cuidar do bebê (Elia, 2004).

O que chega ao bebê através do Outro materno não é um conjunto de significados a serem por ele meramente incorporados como estímulos ou fatores sociais de determinação do sujeito com os quais interagiria, a partir de sua carga genética, na "aprendizagem social" de sua subjetividade. O que chega a ele é um conjunto de marcas materiais e simbólicas significantes - introduzidas pelo Outro materno, que suscitarão, no corpo do bebê, um ato de resposta que se chama sujeito (Elia, 2004, p. 41).

A partir da perspectiva de Lacan sobre o Outro, Melman (1992) faz uma leitura sobre o fenômeno do alcoolismo, da delinquência e da toxicomania pontuando que a coletividade tem o lugar de Outro, uma vez que as estruturas sociais também são simbólicas. A entrada na ordem simbólica por outra via, e não pela ocorrência do recalque primordial dos movimentos pulsionais, seria o cerne da delinquência. "O que caracteriza a delinquência é que o acesso ao objeto é organizado não pelo símbolo, que é o quinhão comum de todos os neuróticos, mas pela apreensão, pelo rapto, pela violação" (Melman, 1992, p. 42).

O mesmo autor assevera ainda que os atos delinquentes são, em certa medida, simbólicos, pois o que está em voga não são apenas os aspectos meramente materiais do delito, mas diferentes ânimos que movimentam os sujeitos nesse sentido. Conforme Melman (1992, p. 44):

As condutas do delinquente são simbólicas de uma falta, e de uma falta essencial, uma vez que é a falta de acesso ao objeto que conta. Não este ou aquele objeto, nem mesmo de objetos dos quais ele faz coleção em sua diversidade heteróclita. Trata-se de uma falta de acesso a este objeto que comanda o gozo, isto é, ao falo. É, portanto, precisamente a falta de tomada pela ordem simbólica, na medida em que esta dá acesso a este objeto essencial, que não deixa o delinquente outro recurso que não seja o do rapto, da apreensão violenta, da violação. Mesmo porque não há para ele outra maneira de entrar em relação com o falo, de detê-lo, de possuir dele uma parte, se deseja manter-se na virilidade.

Pensando a relação do sujeito com a falta e os meios de que se lançam mão para aplacar ou preencher essa lacuna existente, não só quando se pensa no delinquente, mas em qualquer indivíduo, é que o conceito de "sujeito desejante" faz sentido. De acordo com Herzog (2004, p. 47), "o sujeito é designado como desejante, entendendo-se o desejo não apenas como uma busca do que não se tem, do que falta, mas, principalmente, como busca do que nunca se terá [. . .]”. 
É interessante abordar a problemática da "falta" na constituição dos sujeitos, pois, quando se fala dos egressos prisionais, o cuidado consiste em não tratálos como anjos, tampouco como demônios, mas como pessoas que também encerram a humanidade em si. Assim, as noções de sujeito para a Psicanálise ajudam a refletir sobre tais indivíduos de forma desprendida da questão da consciência, esclarecendo que as pessoas podem ocupar diferentes posiçóes subjetivas não passíveis de entendimento meramente pela via da razão.

No caso das pessoas que "deságuam" no sistema prisional, é possível vislumbrar que existem certas confusões subjetivas entre a "falta" e a privação social, as quais resultam numa busca por objetos/coisas por meio do crime numa tentativa de sanar essas desordens ou como um apelo a algo que promova um traço constitutivo. Frente à ditadura midiática que impõe sonhos pré-fabricados e modelos perfeitos de sujeitos de sucesso, o crime seria uma promessa, diante dessas demandas, não cumprida, irreal, mas, ainda assim, uma promessa.

A intenção de abordar diferentes concepções de sujeito dentro da Psicanálise não visa a esgotar o assunto, mas a apresentar a complexidade do tema $\mathrm{e}$ contemplar a dimensão humana também presente nos egressos prisionais. Por conseguinte, destacar a questão sobre a reinserção dos egressos prisionais é um desafio, uma vez que é preciso cuidado para não maximizar a importância do contexto social em detrimento do que é puramente singular e vice-versa, e sim encarar o processo como algo que entrelaça diversos fatores.

No tocante ao retorno à liberdade, esse processo também não se traduz apenas em perspectivas positivas para os egressos prisionais. A existência extramuros institucional da prisão remete a novas demandas a sujeitos egressos que, mesmo depois de terem cumprido a pena, poderão se deparar com o preconceito e a falta de credibilidade perante a sociedade e, consequentemente, com dificuldades de ordem prática para manter a própria subsistência, além de terem que lidar com os aspectos deletérios do aprisionamento na subjetividade humana.

O processo de reinserção social dos egressos prisionais, portanto, abrange peculiaridades que provêm tanto do cenário social, de modo mais amplo, como do âmbito individual da vida desses sujeitos que, de certa forma, foram violados no território do seu eu. Nessa direção, o presente trabalho teve como objetivo compreender como os sujeitos egressos do sistema prisional significam o processo de reinserção social.

\section{MÉTODO}

Esta pesquisa, de caráter qualitativo, utiliza o método interpretativo da Psicanálise. Vale ressaltar que a pesquisa qualitativa compreende "um 
processo personalizado e dinâmico de investigação" (Pinto, 2004, p. 74), fundamentalmente construtivo e interpretativo.

Ainda sobre a pesquisa qualitativa, Turato (2005) confere destaque ao processo de "significação" dos eventos a serem investigados. Para o autor: "O significado tem função estruturante: em torno do que as coisas significam, as pessoas organizarão de certo modo suas vidas [. . .]" (p. 509), ou seja, os significados atribuídos pelas pessoas a determinados fenômenos moldam as suas vivências e constituemse como alvos a serem apreendidos pelo pesquisador, bem como atribuem à pesquisa qualitativa a característica de um campo de múltiplas interpretações, tendo em vista que o pesquisador confere um sentido ao fenômeno apreendido.

A respeito do método interpretativo da Psicanálise, Rosa e Domingues (2010) consideram que "[. . . ] o objeto da pesquisa não é um dado a priori, mas sim produzido na e pela investigação" (p. 182), via interpretação. O trabalho interpretativo permitiu, a partir dos discursos dos participantes, extrair noções sobre as vivências dos egressos prisionais e o processo de reinserção social.

Nesse sentido, a análise das entrevistas considerou o ambiente relacional entre os colaboradores e a entrevistadora desde o convite para participarem da pesquisa até o arranjo teórico das informações, de tal modo que, na relação estabelecida com os colaboradores e o material, alguns temas se destacaram e instigaram maior reflexão ao mobilizar sentimentos, reações e estranhezas de diversas ordens. Nesse percurso contamos com a contribuição de Fédida (1989), que considera que na relação transferencial pode ocorrer o inédito, a incursão nas vivências que não puderam ser elaboradas, além das manifestações do que é impronunciável.

Foram entrevistados sete egressos prisionais da cidade Uberlândia (MG) que estavam, respectivamente, há um, dois, três, seis, nove meses, um ano e mais de sete anos em liberdade, com o intuito de contemplar diferentes momentos desse processo e as mudanças que podem acontecer com o decorrer do tempo fora da prisão.

Foram realizadas entrevistas semiestruturadas, com gravação de áudio e sua posterior transcrição. Os participantes foram acessados por meio do Programa de Inclusão Social de Egressos Prisionais (PrEsp), ao comparecem no referido Programa para assinar o Termo de Apresentação ${ }^{1}$. As pessoas convidadas que aceitaram participar deste estudo leram e assinaram o Termo de Consentimento Livre e Esclarecido, garantindo o caráter voluntário da participação, assim como o respeito às normas éticas que norteiam a realização de pesquisas com seres humanos. O estudo foi submetido e aprovado pelo Comitê de Ética em Pesquisa com Seres Humanos sob o protocolo de número 09028912.6.0000.5152.

1 Mensalmente ou trimestralmente, as pessoas em cumprimento do Regime Aberto ou Livramento Condicional na cidade de Uberlândia (MG) comparecem ao PrEsp para assinar o Termo de Apresentação, além de dar informações sobre endereço, trabalho, estudo etc. 


\section{ANÁLISE E DISCUSSÃO DAS ENTREVISTAS}

Num primeiro momento os sujeitos são apresentados por meio de uma análise descritiva das entrevistas. $\mathrm{Na}$ sequência, são destacados os blocos denominados: "A criminalidade e o recrutamento de jovens"; "O inferno da prisão"; e "O processo de (re)inserção social". O primeiro aborda o fascínio que o crime (especialmente o tráfico de drogas), como um meio de vida, exerce sobre os jovens pobres; o segundo ressalta o período de estadia na prisão, com toda a crueza abarcada por ela; e o terceiro discute sobre a reinserção social dos egressos prisionais e a necessidade de relativizar esse processo.

\subsection{Apresentação dos entrevistados}

Sobre a apresentação dos entrevistados, cumpre dizer que os nomes são fictícios e foram escolhidos por meio da percepção de algumas características dos entrevistados e em razão do significado que possuem em sua origem. Também é possível observar que a maioria dos entrevistados são adultos jovens, com baixa escolaridade e experiências profissionais em trabalhos operacionais, e o tempo de reclusão varia de acordo com o tipo de delito. Em função de tais dados, podese dizer que os participantes do presente estudo representam grande parte das pessoas privadas de liberdade no Brasil.

Tabela 1. Caracterização dos entrevistados.

\begin{tabular}{|c|c|c|c|c|c|}
\hline NOME & $\begin{array}{l}\text { TEMPO EM } \\
\text { LIBERDADE }\end{array}$ & IDADE & ESCOLARIDADE & PROFISSÃO & $\begin{array}{l}\text { TEMPO DE } \\
\text { RECLUSÃO } \\
\text { TIPO DE DELITO }\end{array}$ \\
\hline André & 1 mês & 24 & $\begin{array}{l}\text { Ensino Médio } \\
\text { Incompleto }\end{array}$ & Pintor & $\begin{array}{l}1 \text { anos e } 11 \\
\text { meses }\end{array}$ \\
\hline Zeca & 2 meses & 24 & $\begin{array}{l}\text { Ensino Fundamental } \\
\text { Completo }\end{array}$ & $\begin{array}{l}\text { Atendente e } \\
\text { Pintor }\end{array}$ & $\begin{array}{l}2 \text { anos e } 7 \\
\text { meses }\end{array}$ \\
\hline Amador & 3 meses & 34 & $\begin{array}{l}\text { Ensino Fundamental } \\
\text { Incompleto }\end{array}$ & Serralheiro & $\begin{array}{l}4 \text { anos e } 6 \\
\text { meses }\end{array}$ \\
\hline Renato & 6 meses & 30 & $\begin{array}{l}\text { Ensino Fundamental } \\
\text { Incompleto }\end{array}$ & $\begin{array}{l}\text { Operador de } \\
\text { Máquinas }\end{array}$ & $\begin{array}{l}2 \text { anos e } 4 \\
\text { meses }\end{array}$ \\
\hline Daniel & 9 meses & 28 & $\begin{array}{l}\text { Ensino Médio } \\
\text { Completo }\end{array}$ & $\begin{array}{l}\text { Atendente. } \\
\text { Sócio } \\
\text { Proprietário }\end{array}$ & 1 ano e 7 meses \\
\hline Fagundes & 12 meses & 27 & $\begin{array}{l}\text { Ensino Fundamental } \\
\text { Incompleto }\end{array}$ & $\begin{array}{l}\text { Pedreiro, } \\
\text { Pintor e } \\
\text { Operador de } \\
\text { Máquinas }\end{array}$ & $\begin{array}{l}4 \text { anos e } 7 \\
\text { meses }\end{array}$ \\
\hline Lázaro & 7 anos & 36 & $\begin{array}{l}\text { Ensino Fundamental } \\
\text { Incompleto }\end{array}$ & Motorista & 2 meses \\
\hline
\end{tabular}

Fonte: Elaboração dos autores. 
Considerando o processo interpretativo contínuo das entrevistas, para cada entrevistado surgiram enunciados que chamaram mais a atenção dentro da relação transferencial, sendo destacados nesta pesquisa.

André - um mês em liberdade -, no momento em que foi feito o convite para participar da pesquisa, se apresentou disponível e questionou: "Posso falar tudo mesmo?”. Ao lançar essa pergunta, estaria ele me precavendo do conteúdo que teria a dizer? É como se ele dissesse: "Você vai suportar ouvir o que tenho a dizer?". Outro modo de pensar sobre o questionamento inicial de André seria relacionado ao fato de ele se certificar sobre o uso das informaçóes que seriam repassadas. Considerando algumas denúncias e a ambivalência dos sentimentos que André apresenta durante a entrevista, interpretamos que realmente ele não pode nos dizer tudo sobre suas vivências; se diz algo, é porque "escapa”, pois, especialmente, também retrata o descaso estatal com quem está preso.

Já o entrevistado Zeca - dois meses em liberdade - encontra uma solução mágica de alta rentabilidade por meio do crime, sem ponderar os riscos e prejuízos que podem acometê-lo. Ao analisar as características salientadas por Zeca, a vida em liberdade, para ele, parece não apresentar perspectivas de romper um ciclo de reentradas prisionais.

Amador - três meses em liberdade - vivenciou a fase de luto dentro da prisão, em virtude da perda da esposa em um acidente, e traz uma noção diferenciada sobre a prisão como amparo. Conforme Amador, esse espaço serviu não apenas como contenção de física que o impedia de ter contato com a realidade externa, de chegar em casa e não encontrar a esposa, como também foi uma forma de amparo por meio do apoio e dos vínculos que construiu com os companheiros de cela. Para Amador, a liberdade se configurou como aterrorizadora, ou seja, ele perde o suporte recebido na prisão, sendo que o retorno à liberdade passa a ser visto como algo problemático.

Já Renato - seis meses em liberdade - utiliza a expressão "cair" insistentemente ao falar das várias passagens pelo sistema prisional. $\mathrm{O}$ termo cair/recair é muito comum no processo de dependência química, sendo que, no caso de Renato, parece haver uma correlação bem estreita entre as drogas e a prisão, caso em que cair parece indicar também "cair nas mãos da polícia ou da lei". Isso nos sugere que ele faz uma associação entre o aprisionamento e o uso que fazia de drogas, de forma que a primeira seria regida pelos mesmos motivos que a segunda.

O entrevistado Daniel - nove meses em liberdade - trata a última entrada prisional como um "vacilo" que pensava que nunca mais iria acontecer; no entanto, parece que conseguiu "êxito" com o ingresso na criminalidade, pelo menos financeiramente. Sobre sua guinada financeira, Daniel relata: "A gente 
foca no dinheiro e esquece o resto". O resto, nas próprias palavras de Daniel, seria a honestidade. Ele expõe o retorno ao crime com um propósito definido, mas com o preço de perder aquilo que, longe de ser o "resto" no sentido pejorativo, seria o mais importante para Daniel, incluindo sua família, boa imagem social e honestidade. Em liberdade, o entrevistado fala sobre resgatar esse "resto" que teria sido perdido e se configura como algo de muito valor para ele nesse novo período da sua vida.

Fagundes - 12 meses em liberdade -, durante a entrevista, procura sustentar sua masculinidade ao discorrer sobre suas relações amorosas, sempre no plural, e ao contar sobre os seus crimes, sobretudo os homicídios. Ao longo da conversa, a imagem de virilidade que Fagundes tenta expor não se sustenta sozinha. Paradoxalmente, a fragilidade começa a coabitar nos seus discursos, sendo que, após sair da prisão, Fagundes teve um filho - o nascimento da criança o teria colocado numa condição contraditória: o criminoso absoluto onipotente se tornaria vulnerável e frágil na figura de pai.

Por fim, Lázaro - há mais de sete anos em liberdade - foi o único entrevistado que se declarou inocente. Ele narra sobre o sentimento de injustiça e muito sofrimento dentro da prisão. Para Lázaro, mesmo após tantos anos, ainda possui um sentimento de revolta, sendo que a satisfação de estar em liberdade não exclui as recordações da experiência do aprisionamento.

Finalizada a breve apresentação dos colaboradores da pesquisa, passa-se agora à exposição dos temas que também surgiram do processo de análise das entrevistas. Sem a pretensão de categorizar este estudo, com tais blocos procuramos organizar temas presentes em todos os entrevistados, em sua relação com os objetivos do presente trabalho.

\subsection{A criminalidade e o recrutamento de jovens}

O fenômeno da criminalidade e o contato precoce dos entrevistados com essa realidade é algo que também envolve a problemática dos egressos prisionais, sendo que a maioria dos entrevistados apresentou relatos sobre o ingresso no crime na adolescência ou na juventude. Entre os discursos aparecem certas restrições materiais, em alguns depoimentos de forma mais severa e em outros, de maneira mais comum, porém o que marca substancialmente as narrativas é a ânsia por "algo mais". Às vezes é algo da ordem do querer mimético (porque o outro tem, eu gostaria de ter também), em outras situações é um querer simplesmente por querer ou, ainda, para manutenção do uso de drogas e/ou de despesas da casa. $\mathrm{O}$ ponto-chave é que o "algo mais" sempre é algo que os entrevistados supõem ser o melhor para eles. Seguem alguns exemplos. 
Você vê um vizinho seu que tem um Super Nintendo e você não ganha. Seu vizinho tem uma bicicleta e você não tem (André).

[. . .] era mesmo só pra eu curtir mesmo, pra eu ir nos "frevos", pra eu comprar as roupas pra mim, uns negocinhos pra mim. Porque eu nunca gostei de trabalhar, pra falar a verdade, mas... (Zeca).

É um querer ter as coisas boas (Amador).

Eu gosto de festa onde só vai gringo. Eu falo assim, gente de classe mais alta. É festa cara (Fagundes).

Algumas situações fazem a gente querer crescer na vida (Daniel).

Destaca-se, a priori, a fala de Zeca, o qual conta que seu delito (tráfico de drogas) foi um meio que encontrou para ter condiçóes de aproveitar o que é próprio da juventude, tendo em vista que ele revela não gostar de trabalhar. Ele aponta um desapreço pelo trabalho e um funcionamento mental que não aceita a postergação do prazer; logo, esse discurso é claramente hedonista: o entrevistado quer os frevos, curtir, ter roupas boas, mas não quer pagar o preço que a sua condição social exige para isso. Pode-se observar, assim, que no âmbito da nossa sociedade mercantilista as propagandas voltadas para o público juvenil intensificam o querer "ter", ditando modelos do que é bom, bonito e que não pode ser adiado.

Em contraposição ao discurso de Zeca, acrescenta-se a fala de Renato sobre o destino do dinheiro obtido por meio do crime: "Uma porcentagem eu ajudava dentro de casa, e com a outra porcentagem eu usava droga". Tal narrativa remete ao fenômeno de criminalização da pobreza abordado anteriormente na introdução e que é tão marcante em nosso país, especialmente quando se observa que o sistema judiciário brasileiro recai desproporcionalmente sobre os pobres.

Sobre esse aspecto, Guareschi (2004) discorre acerca do processo de entrada, especialmente de jovens, na economia criminosa, sendo uma forma de acessar bens materiais e seguir um padrão de vida considerado bom. As perspectivas de vida e contextos nos quais as ofertas para o ingresso na vida criminosa são grandes, aliadas ao desejo de participar de eventos, de padrões de vida que não pertencem à realidade social da qual provêm. Se forem associados, tais fatores conduzem ao recrutamento, sobretudo de jovens, para a criminalidade por meio da "integração perversa” (Guareschi, 2004, p.150).

Além disso, cobra-se dos sujeitos um ideal de vida cujo acesso a todos a própria organização social não permite. Dessa forma, para os entrevistados, o 
crime encaixa-se como um movimento de rompimento de regras sociais e um meio de pleitear uma nova condição vida ou um novo lugar no mundo.

Nesse ponto é importante retomar a discussão sobre sujeito apresentada anteriormente, tendo em vista que a associação do processo dialético utilizado por Ogden (1996) às reflexões sobre as várias formas de se pensar a constituição do sujeito confere uma fluidez relevante para entender as contradições (que não se excluem, mas se complementam) - especialmente entre subjetividade e intersubjetividade -, as quais sustentam um modo de ser e estar no mundo possível, frente à tragicidade que a história da maioria dos egressos prisionais contempla.

\subsection{O inferno da prisão}

Os relatos sobre as vivências dentro da prisão tiveram ênfase nos discursos dos entrevistados. O primeiro aspecto de destaque sobre as narrativas dessa fase é a tonalidade que eles conferem a tal experiência. Todos, independentemente do tempo transcorrido após a saída do cárcere, relatam sobre esse momento de forma bastante vívida e como se fosse algo bastante recente.

André foi um dos entrevistados que mais discorreu sobre as mazelas da prisão, apontando o ambiente da prisão como um lugar desumano para a habitação:

O que acontece, [é que a prisão] é um lugar que é porco, que funciona há 10 anos e eles nunca jogaram uma tinta, nunca desinfetaram, nunca fizeram nada pra conservar, entendeu? Então, bactéria ali é "mato", é muita, né? Vira e mexe você vê um com uma "zica" ${ }^{2}$, uns trens, uns colchões que... Nossa! Eu tô falando aqui, até "pinica”"

Sá (2005) discorre sobre a prisão e classifica graves problemas carcerários em dois grandes grupos. O primeiro diz respeito à má gestão da coisa pública, que acarreta problemas como presídios sem a infraestrutura mínima necessária (material e humana) e superpopulação carcerária. Enquanto isso, o segundo grupo é inerente à própria natureza da pena privativa de liberdade, ou seja, o isolamento do preso, a sua segregação da sociedade, a convivência forçada no meio delinquente, entre outros.

Foucault (1987) assevera que a cadeia exerce um controle não apenas sobre o corpo dos presos, impedindo-os de ir e vir normalmente no meio da sociedade mais ampla, mas também em suas disposições pessoais - pensar, agir, sentir e falar.

\footnotetext{
2 "Zica", para o entrevistado, significa doença, especialmente as que são mais fáceis de serem contraídas devido à falta de higienização.

3 "Pinica" é forma flexionada do verbo "pinicar". Tal palavra foi empregada por André no sentido de sentir coceira e incomodo só pelo fato de lembrar do ambiente da prisão.
} 
Nesse entremeio, Baratta (2002) discorre sobre o processo de "aculturação" que as pessoas sofrem ao ingressarem no ambiente prisional, ou seja, a incorporação de aspectos como valores, atitudes e comportamentos da cultura carcerária. Um exemplo é que, ao relatar sobre a prisão, o linguajar utilizado pelos entrevistados aparece carregado de gírias.

Lázaro, entrevistado que estava há mais de sete anos em liberdade, fala sobre o processo de adaptação dentro da cadeia e as mudanças, salientando o modo de falar. Veja o exemplo: Você fala "irmão". Quando você está preso, você fala “irmão". Lá [na cadeia] você não fala "cela", você fala "X" (Lázaro).

Destacam-se, nas falas dos entrevistados, o modo como nomeiam a prisão e os sentimentos que possuem lá dentro. Para alguns faltam palavras, para outros resta a tentativa de encontrar expressões para nomear o inominável:

Lá é tipo assim, eu não conheço o inferno, não, mas eu posso te garantir que lá é um pedacinho dele. (André)

Lá dentro a gente sente falta de tudo. Eu vou te falar um negócio: lá dentro, o sentimento da gente é de tipo... (Renato)

Sentimento de revolta, revolta. Lá é um pedacinho do inferno na Terra. Porque você sofre demais; muito sofrimento, muita humilhação. (Lázaro)

Lá dentro tem muita maldade. Se você quer saber, eu vou falar a verdade mesmo. Lá dentro tem muita maldade: eu quando estava lá dentro, falava que queria sair matando todo mundo. (Fagundes)

Deve-se acrescentar que o termo "inferno" decorre do latim infernus e diz respeito às profundezas ou ao mundo inferior. Nesse sentido, as comparações de aspectos da prisão a algo que remete à classe animal também foi algo comum. A cela foi comparada à gaiola por Fagundes; alguns pavilhões mais agitados foram nomeados de caldeirão por Zeca; e a comida é considerada pior que lavagem, para Lázaro. Essas menções indicam, ainda, o quanto eles sentiam o ambiente prisional como um lugar subumano para estadia.

Vários autores como Sá (2005), Wacquant (2001) e Zaluar (1999) asseveram sobre as condiçôes degradantes de habitabilidade das prisóes. No entanto, as falas dos entrevistados vão além das confirmações teóricas que tratam desse assunto: há abordagens sobre as suas vivências e apontamentos sobre o quanto elas continuam vivas dentro deles. 
Também emergiram relatos sobre a criação de utensílios e até mesmo acerca da fabricação de "pinga" ou do uso da maconha dentro do ambiente prisional, aspectos que são úteis para minimizar a condição de calamidade em que vivem, tamponar o sofrimento e tornar a vida na prisão dentro dos limites do suportável. A invenção e o uso da criatividade na fabricação de diversos instrumentos dentro da prisão podem ser entendidos como um movimento de resistência que surge a partir das necessidades dos sujeitos.

Considerando essa situação, pode-se afirmar que dentro da cadeia as fronteiras entre o ilegal e o legal são frágeis ou não existem, e a prisão possui um modo de funcionar peculiar, com normas e leis oportunas. Particularmente no que diz respeito à presença de drogas dentro do ambiente prisional, Guimarães, Meneghel e Oliveira (2006, p. 640) asseveram que:

A naturalização das drogas na prisão é uma alternativa criminosa de grande utilidade para a instituição, pois auxilia o controle prisional por funcionar como agente de contenção de rebeliōes e fugas, uma prática (in)conscientemente validada pelos administradores e agentes penitenciários.

\section{O PROCESSO DE (RE)INSERÇÃO SOCIAL}

O universo social do qual o egresso provém e para o qual ele retornará após a experiência do cárcere não sofre grandes modificações. Ao regressar, ele reencontrará os fascínios que a criminalidade oferece; assim, tal cenário fará parte do seu processo de reinserção social.

Além da proximidade com a criminalidade, o egresso deverá lidar com as demandas abarcadas pela vida na sociedade mais ampla. Entre elas podem-se destacar os relacionamentos com os familiares (pai, mãe, irmãos, esposa, filhos); os relacionamentos socioafetivos mais amplos (vizinhos e parentes); a manutenção das despesas pessoais e da família; o ingresso no mercado de trabalho e as demais pendências que podem ter sido deixadas para trás.

Ainda que tenham surgido diferentes discursos sobre a recepção pelos familiares, a realidade que se apresenta para a maioria das pessoas que saem das prisões se refere ao não conhecimento, por parte dos familiares, sobre a saída de tais indivíduos ou a inexistência de suporte familiar com o qual possam contar. Outro agravante é o fato de a saída do egresso ser uma surpresa nem sempre agradável, especialmente quando representa o aumento do custo familiar (Carvalho Filho, 2006).

Sobre a saída da prisão, o reencontro com familiares e outros relacionamentos socioafetivos mais amplos, cabe ressaltar que houve uma ambiguidade: ora os 
entrevistados dizem terem sido bem recepcionados, ora relatam que se tornaram bodes expiatórios dos ambientes dos quais fazem parte. Isso pode ser observado nos relatos de Fagundes e Zeca:

Depois que eu saí da cadeia eu pedi para minha mãe deixar eu morar com ela [. . .]. Ela deixou e falou que eu ia ter que mudar meu jeito de vestir, de falar. Até meu jeito de falar eu tive que mudar depois que eu fui morar com minha mãe; antes eu falava muita gíria (Fagundes)

Tudo que acontece, se acontecer alguma coisa, se sumir alguma coisa, o povo já acha que sou eu. Não sou eu, mas eles acham que sou eu (Zeca).

No que se refere aos relacionamentos socioafetivos mais amplos com vizinhos, conhecidos ou parentes dos entrevistados, todos eles relataram sobre situações em que sentiram discriminados de modo velado ou não, o que coaduna com os dizeres de Goffman (1978), que aponta a capacidade de o estigma inferiorizar e rebaixar as pessoas rotuladas. Ao falarem sobre o assunto, os entrevistados pontuaram comentários preconceituosos, olhares de desconfiança ou até mesmo ocasióes em que foram maltratados por serem ex-detentos.

Independentemente do tempo transcorrido após a saída da prisão, as vivências do cárcere ainda parecem de forma vívida para os entrevistados. $\mathrm{O}$ que aparentemente os diferencia são as principais atividades desenvolvidas e as perspectivas para o futuro: não seriam fatores relacionados ao tempo fora da prisão, mas às experiências próprias de cada um.

Para além dos conteúdos que os entrevistados destacaram a respeito de projetos e sonhos futuros, fica a impressão de que os discursos sobre esse tema são esvaziados e não coincidem com as possibilidades concretas que eles possuem. $\mathrm{Ou}$ seja, as perspectivas para o futuro aparecem mais como um discurso socialmente aceitável do que como planos de vida, especialmente quando discorrem sobre voltar a estudar e buscar um emprego lícito.

Acerca dessa questão, é possível apresentar como exemplo a situação de Renato que, durante a entrevista, fala sobre uma problemática relacionada ao período em que está fora da prisão: "O que eu quero realmente da minha vida?". Renato se questiona se realmente irá empreender uma mudança e buscar romper com o ciclo de reentradas prisionais ou se irá "maquiar" a vida por meio de um emprego aceitável para o pai - que é uma figura importante para Renato -, enquanto continua a praticar outros delitos. 
A problemática maior após o aprisionamento (e que não foi explicitada diretamente) não se trata da reinserção social numa sociedade que nunca acolheu tais indivíduos, mas de um reingresso ou não para a criminalidade.

O entrevistado Zeca, por exemplo, discorre sobre várias possibilidades de se rearranjar fora do crime, no entanto manifesta indignação sobre o salário mínimo, remuneração que é concedida para os trabalhadores legalizados: "Pra trabalhar e ganhar um salário que o povo ganha aí, trabalhando do jeito que o povo trabalha, pra mim ainda não entrou na minha mente isso aî". Sendo assim, ao mesmo tempo em que Zeca fala das possibilidades de se manter fora do crime, ele rejeita essa hipótese dizendo que não se sujeitaria a ganhar pouco.

Portanto, considerando os impasses e as ambiguidades vivenciadas pelos entrevistados quando retornam à liberdade, a palavra (re)inserção deve ser grafada com os parênteses no prefixo "re". E ela parece fazer sentido apenas quando a criminalidade também é um meio e/ou uma possibilidade de esses sujeitos se sentirem, de fato, pertencentes a algum grupo.

\section{CONCLUSÕES (OU À GUISA DE CONCLUSÕES)}

Entre os significados do prefixo "re" na constituição das palavras se encontra o sentido de repetição. Obviamente, algo só pode ser considerado repetido se ocorreu antes. No entanto, quando se ouve falar, de maneira desatenta, sobre a reinserção das pessoas que estiveram algum tempo em privação de liberdade, o que parece óbvio não é tão evidente assim. Se a expressão reinserção social é utilizada para tratar do processo de retorno à liberdade dos sujeitos após o aprisionamento, isso significa que anteriormente, na fase pré-penal, esses sujeitos estiveram inseridos na sociedade. Assim, surge uma nova questão: que tipo de inserção foi essa anterior à prisão?

Como já foi discutido na introdução, sabe-se que as pessoas que mais facilmente caem nas malhas da justiça no Brasil provêm das periferias das cidades que formam os cinturões de pobreza do nosso país. Se tais pessoas são oriundas desses locais, o próprio termo "periferia" já denuncia que, ao falar sobre inserção social, faz-se necessário ponderar se supostamente existiu uma condição de inserção que tenha ocorrido nos moldes do que é possível quando se vive à margem da sociedade, tanto geográfica quanto socialmente. Portanto, pode-se até pensar em inserção social, mas de uma maneira que ocorreria pelo avesso do que é aceito ética e moralmente - por meio do crime, da violência e da rebelião.

Nesse entremeio, a situação das pessoas dentro do ambiente carcerário também pode, por mais absurdo que possa parecer, significar uma forma de amparo e 
inclusão, especialmente quando se observa que os entrevistados trazem relatos de apoio, companheirismo e identificação entre os colegas de cela. A prisão é um recinto que, a partir da contenção do espaço físico, insere as pessoas numa ordenação própria à qual o indivíduo precisa adaptar-se para se manter vivo e da qual é difícil se desvencilhar.

Destarte, quando se aborda a questão da (re)inserção social dos egressos do sistema carcerário, faz-se necessário colocar um parêntese que abre discussões sobre uma realidade social tecida mais prioritariamente por mecanismos segregadores do que por movimentos de inclusão. 


\section{REFERÊNCIAS}

Baratta, A. (2002). Criminologia crítica e crítica do direito penal: uma introdução à sociologia do direito penal. (3a ed.). Rio de Janeiro: Editora Revan - Instituto Carioca de Criminologia.

Brasil. Ministério da Justiça. (2007). Sistema de Informaçôes Penitenciárias (INFOPEN). Recuperado a partir de http://www.infopen.gov.br/.

Carvalho Filho, M. J. (2006). Te prepara pra sair! - síntese analítica sobre a situação dos egressos do sistema penitenciário brasileiro. Recuperado a partir de http://www.ces.uc.pt/lab2004/inscricao/pdfs/painel38/MiltonFilho.pdf.

Elia, L. (2004). O conceito de sujeito. Rio de Janeiro: Zahar.

Fédida, P. (Org). (1989). Comunicação e representação: novas semiologias em psicopatologia. São Paulo: Escuta.

Foucault, M. (1987). Vigiar e punir: história da violência nas prisôes. Petrópolis: Vozes.

Freud, S. (1914/1996). Recordar, repetir e elaborar. In J. Salomão \& O. C. Muniz (Trads.) Obras completas (Vol. 12, pp. 159-171) Rio de Janeiro: Imago. (publicado originalmente em 1914).

Freud, S. (1915/1996). As pulsões e suas vicissitudes. In J. Salomão \& O. C. Muniz (Trads.) Obras completas (Vol. 14, pp. 114 - 144) Rio de Janeiro: Imago. (Publicado originalmente em 1915).

Freud, S. (1938/1940/1996). Esboço de Psicanálise. In J. Salomão \& O. C. Muniz (Trads.) Obras completas (Vol. 23, pp. 151-160) Rio de Janeiro: Imago. (Publicado originalmente em 1938/1940).

Goffman, E. (1978). Estigma: notas sobre a manipulação da identidade deteriorada. (2a ed). Rio de Janeiro: Zahar.

Goffman, E. (2008). Manicômios, prisões e conventos. (8a ed). São Paulo: Perspectiva.

Guareschi, P. A. (2004). Pressupostos psicossociais da exclusão: competitividade e culpabilização. In B. B., Sawaia (Org.). As artimanhas da exclusão: análise psicossocial e ética da desigualdade social. (pp. 141-156). Petrópolis: Vozes, 2010.

Guimarães, C. F.; Meneghel, S. N. \& Oliveira, C. S. de. (2006). Subjetividade e estratégias de resistência na prisão. Psicologia Ciência e Profissão, 26(4), 632645. 
Herzog, R. (2004). O laço social na contemporaneidade. Revista Latino Americana de Psicopatologia Fundamental, 7(3), 40-55.

Klein, M. (1935/1996). Uma contribuição para a psicogênese dos Estados Maníacos-Depressivos. In M. Klein. Amor, culpa e reparação. Rio de Janeiro: Imago.

Lacan, J. (1966/1988). In V. Ribeiro (Trad.) Escritos. Rio de Janeiro: Zahar.

Lei n. 7.210 de 11 de julho de 1984 (1984, 11 de Julho). Institui a Lei de Execução Penal. Diário Oficial da União, Brasília. Recuperado a partir de http://www.planalto.gov.br/ccivil_03/leis/l7210.htm.

Melman, C. (1992). Alcoolismo, delinquência, toxicomania: uma outra forma de gozar. In P. Rosane (Trad.). São Paulo: Escuta.

Ogden, T. H. (1996). Os sujeitos da psicanálise. São Paulo: Casa do Psicólogo.

Pinto, E. B. (2004). A pesquisa qualitativa em psicologia clínica. Psicologia USP, São Paulo; 15(1/2), 71-80.

Rosa, M. D. \& Domingues, E. (2010). O método na pesquisa psicanalítica de fenômenos sociais e políticos: a utilização da entrevista e da observação. Psicologia \& Sociedade, 22(1), 180-188.

Sá, A. A. (2005). Sugestão de um esboço das bases conceituais para o Sistema Penitenciário Federal. São Paulo: Escola de Administração Penitenciária do Estado de São Paulo, 1-20. Recuperado a partir de http://www.sap.sp.gov.br/ download_files/reint.../sugestao_esboco.doc.

Turato, E. R. (2005). Métodos qualitativos e quantitativos na área da saúde: definiçōes, diferenças e seus objetos de pesquisa. Revista Saúde Pública, 39(3), 507-514.

Wacquant, L. (2001). As prisões da miséria. Rio de Janeiro: Zahar.

Winnicott, D. W. (1951). Objetos transicionais e fenômenos transicionais. In D. W., Winnicott (Org.). Textos selecionados: da pediatria à psicanálise. Rio de Janeiro: Francisco Alves, 1978.

Zaluar, A. (1996). Da revolta ao crime. São Paulo: Moderna. 